\title{
Suckling Rats Actively Recycle Carbon from $\alpha$-Linolenate into Newly Synthesized Lipids Even During Extreme Dietary Deficiency of n-3 Polyunsaturates
}

\author{
STEPHEN C. CUNNANE, MARY ANN RYAN, YU HONG LIN, SUN-YOUNG LIM, AND NORMAN SALEM, JR.
}

\begin{abstract}
Research Center on Aging [S.C.C., M.A.R.], Sherbrooke University Geriatric Institute, Sherbrooke, Québec J1H 4C4, Canada; Laboratory of Membrane Biochemistry and Biophysics [Y.H.L., N.S. Jr.], National Institute of Alcoholism and Alcohol Abuse, Rockville, Maryland 20852; Division of Ocean Science [S.-Y. L.], Korea Maritime University, Pusan 606-791, Korea
\end{abstract}

\begin{abstract}
Docosahexaenoate is usually considered to be the principal endpoint of $\alpha$-linolenate metabolism in mammals. Nevertheless, several studies over the past $30 \mathrm{y}$ have shown that more carbon from $\alpha$-linolenate is recycled into newly synthesized lipids than is used to make docosahexaenoate. Our objective in this study was to assess carbon recycling from $\alpha$-linolenate in suckling rats made deficient in n-3 polyunsaturated fatty acids (PUFA). Female Long-Evans rats were given a diet deficient in n-3 PUFA at weaning and then bred 8 wk later. Pups from the second generation were nursed by their respective dams and gavaged with $1 \mathrm{mg}\left[\mathrm{U}-{ }^{13} \mathrm{C}\right]-\alpha-$ linolenate at $10 \mathrm{~d}$ old. Brain and liver were obtained $24 \mathrm{~h}$ later, and the fatty acid profiles and ${ }^{13} \mathrm{C}$ enrichment analyzed. Docosahexaenoate was markedly depleted in brain $(-82 \%)$ and liver $(-97 \%)$ of the n-3 PUFA-deficient rats. In the controls, ${ }^{13} \mathrm{C}$ enrichment in products of carbon recycling (cholesterol and fatty acids other than n-3 PUFA) exceeded that in docosahexaenoate by 2.4 -fold (liver) and 7.5 -fold (brain). n-3 PUFA deficiency reduced the ratio of ${ }^{13} \mathrm{C}$ enrichment in products of carbon recycling compared with ${ }^{13} \mathrm{C}$ incorporated into docosahexaenoate by $63 \%$ in the brain but not in the liver. Despite severe n-3 PUFA deficiency, carbon recycling still consumed $50 \%$ more ${ }^{13} \mathrm{C}$ from $\alpha$-linolenate than went into docosahexaenoate in the liver and 2.8-fold more in the brain. We conclude that carbon recycling is an integral part of neonatal metabolism of $\alpha$-linolenate and is not simply an overflow pathway arising from excess availability of preformed docosahexaenoate. (Pediatr Res 59: 107-110, 2006)
\end{abstract}

$\mathrm{S}$ tudies evaluating the whole body homeostasis of polyunsaturates (PUFA) in a variety of nutritional and metabolic states demonstrate that $\beta$-oxidation as a fuel is the quantitatively dominant route of use of both linoleate and $\alpha$-linolenate $(1,2)$. In addition to complete oxidation to $\mathrm{CO}_{2}$, studies using isotopically labeled linoleate and $\alpha$-linolenate show that a considerable amount of partially oxidized carbon from these two fatty acids is incorporated into newly synthesized lipids rather than being fully $\beta$-oxidized to $\mathrm{CO}_{2}$. This "carbon recycling" pathway has been most commonly studied using labeled $\alpha$-linolenate injected or gavaged into suckling rats (3-7), but parallel results have been reported in models

Received April 26, 2005; accepted July 1, 2005.

Correspondence: Stephen C. Cunnane, Ph.D., Research Center on Aging, Sherbrooke University Geriatric Institute, 1036 Belvedere South, Sherbrooke, QC, Canada J1H 4C4; e-mail: stephen.cunnane@usherbrooke.ca

DOI: 10.1203/01.pdr.0000190569.07991.ed varying from astrocytes in culture (8), to pregnant rats $(1,8 \mathrm{a})$, infant rhesus monkeys (9), and humans (10).

Three features of carbon recycling from $\alpha$-linolenate are consistently observed: 1) it occurs in several different organs at levels exceeding the desaturation chain elongation of the parent to the long chain n-3 PUFA by five- to 200-fold (7), 2) it is particularly evident in the neonatal period, $(3-7,9)$ and 3$)$ it occurs prominently whether or not the main longer chain PUFA are present in the diet $(7,9,10)$ or culture medium (8). These features suggest that carbon recycling is a quantitatively important pathway in the metabolism of $\alpha$-linolenate, but the function of this pathway remains enigmatic.

Linoleate recycling is largely unaffected even by extreme deficiency of all dietary n-6 PUFA (11), but whether $\alpha$-linolenate recycling is affected by deficient intake of all n-3 PUFA has not yet been established. The objective of the present study was therefore to quantify the magnitude of carbon recycling of $\left[\mathrm{U}_{-}{ }^{13} \mathrm{C}\right]-\alpha$-linolenate in rat pups that were born to dams that were extremely deficient in n-3 PUFA. Maternal consumption of a diet maximally deficient in n-3 PUFA was necessary to reduce the tissue content of docosahexaenoate in the suckling rat pups as much as possible. It was hypothesized that studying carbon recycling from $\alpha$-linolenate in rat pups made n-3 PUFA deficient would clarify whether this pathway was simply an "overflow" pathway occurring because of abundant availability of preformed docosahexaenoate (in milk or from neonatal synthesis) or was integral to neonatal metabolism of $\alpha$-linolenate independent of n-3 PUFA status. We provided an abundant source of dietary docosahexaenoate both to mimic rat milk and to have a clear contrast in docosahexaenoate supply versus the deficient group.

Among the n-3 PUFA, it is principally docosahexaenoate that is important for normal neonatal development $(12,13)$. Accordingly, our measure of the magnitude of carbon recycling from $\alpha$-linolenate was appearance of ${ }^{13} \mathrm{C}$ in docosahexaenoate compared with ${ }^{13} \mathrm{C}$ recovered in newly synthesized lipids in the liver or brain of the suckling rats.

Abbreviations: GC, gas chromatograph(y); PUFA, polyunsaturated fatty $\operatorname{acid}(\mathrm{s})$ 


\section{METHODS}

The animal handling protocol was approved by the NIAAA Animal Care and Use Committee. Three-week-old female Long-Evans hooded rats were obtained from a commercial supplier (Charles River, Portage, MI) and maintained under conventional conditions at $23 \pm 1{ }^{\circ} \mathrm{C}$, with a 12-h light-dark cycle. Drinking water and custom-pelleted diets were provided on an ad libitum basis. Groups of 60 females each were immediately placed on either a control diet containing adequate levels of n-3 PUFA or a diet maximally depleted of n-3 PUFA (Table 1). A large number of dams were used as this was part of a larger experiment (14). At $11 \mathrm{wk}$ of age, the dams were paired with 12-wk-old Long-Evans proven male breeders for a period of 1 wk. During this period and after mating, the females continued on their respective diets. Dams were housed three/cage until near their time of delivery at which time they were individually housed.

When the second-generation female pups were $10 \mathrm{~d}$ old, one pup from each of 10 separate litters was taken randomly from dams on each of the two diets. The pups were gavaged with a single oral dose of $1 \mathrm{mg}\left[\mathrm{U}-{ }^{13} \mathrm{C}\right]-\alpha$-linolenate dissolved in $100 \mu \mathrm{L}$ olive oil. The pups were returned to their respective dams and then killed $24 \mathrm{~h}$ later by decapitation. The brain and liver were rapidly excised and stored at $-80^{\circ} \mathrm{C}$ until analyzed. Use of a similar tracer protocol in suckling rats previously revealed clear evidence of carbon recycling from $\left[\mathrm{U}-{ }^{13} \mathrm{C}\right]-\alpha$-linolenate $(6,7)$. Two undosed rat pups from dams on each of the two diets served as controls for background ${ }^{13} \mathrm{C}$ enrichment.

Total lipids in the brain and liver of each rat pup were extracted into chloroform:methanol (2:1, vol:vol) as previously described (6). Two aliquots of each lipid extract were prepared, one containing heptadecanoic acid as internal standard for fatty acid quantification and one without the internal standard for ${ }^{13} \mathrm{C}$ analysis. Following saponification of the total lipid extracts, fatty acid methyl esters were prepared using $\mathrm{BF}_{3}$-methanol and analyzed by capillary gas chromatography (GC) (6). Total sterols (mainly cholesterol) from the brain were extracted and derivatized for analysis by $\mathrm{GC}(15) .{ }^{13} \mathrm{C}$ enrichment in individual fatty acids in the liver and brain and in brain cholesterol was determined by GC-combustion isotope ratio mass spectrometry as previously described (15). The fatty acid and sterol data are given as $\mathrm{mg} / \mathrm{g}$ liver or brain. The ${ }^{13} \mathrm{C}$ enrichment data are given as $\mathrm{ng}{ }^{13} \mathrm{C} /$ whole liver

Table 1. Composition of the control and n-3 PUFA-deficient (Deficient) diets

\begin{tabular}{lcc}
\hline Ingredient $(\mathrm{g} / 100 \mathrm{~g}$ diet $)$ & Control diet & Deficient diet \\
\hline Casein, vitamin free* & 20 & 20 \\
Cornstarch & 15 & 15 \\
Sucrose & 10 & 10 \\
Dextrose & 19.9 & 19.9 \\
Maltose-dextrin & 15 & 15 \\
Cellulose & 5 & 5 \\
Salt-mineral mix $\dagger$ & 3.5 & 3.5 \\
Vitamin mix & 1 & 1 \\
L-Cystine & 0.3 & 0.3 \\
Choline bitartrate & 0.25 & 0.25 \\
TBHQ & 0.002 & 0.002 \\
Fat: & 10 & 10 \\
Coconut oil, hydrogenated & 7.45 & 8.1 \\
Safflower oil & 1.77 & 1.9 \\
Flaxseed oil & 0.48 & 0.0 \\
DHASCO & 0.3 & 0.0 \\
Fatty acid composition $(\%) \S$ & & \\
Saturates & 72.7 & 78.1 \\
Monounsaturates & 5.7 & 4.5 \\
Linoleate & 14.8 & 15.1 \\
$\alpha$-Linolenate & 3.0 & 0.09 \\
Docosahexaenoate & 1.45 & $\mathrm{ND}$ \\
\hline
\end{tabular}

* Dyets Inc. catalogue \#400625.

$\dagger$ Dyets Inc. catalogue \#210025.

$\ddagger$ Dyets Inc. catalogue $\# 310025$.

$\S$ Only trace quantities $(<0.01 \%)$ of $20: 4 n-6,20: 5 n-3$, and $22: 5 n-3$ were detected.

TBHQ, tert-butylhydroquinone; DHASCO, marine microalgal oil (Martek Biosciences, Columbia, MD); ND, not detected $(<0.001 \%$ of total fatty acids). or brain $(6,10)$. The data are expressed as mean \pm SEM for $n=10$ samples/group and were compared statistically by $t$ test.

\section{RESULTS}

Compared with controls, there was 97\% less docosahexaenoate $(\mathrm{mg} / \mathrm{g})$ in the liver (Table 2$)$ of the n-3 PUFAdeficient group. In the n-3 PUFA-deficient rat pups, ${ }^{13} \mathrm{C}$ enrichment in liver $\alpha$-linolenate was $67 \%$ lower and was not reliably detectable in liver eicosapentaenoate (Table 2). On the other hand, the n-3 PUFA-deficient group had 2.8 times more ${ }^{13} \mathrm{C}$ enrichment in liver $\mathrm{n}-3$ docosapentaenoate, but, due to wide variation in the data, there was similar ${ }^{13} \mathrm{C}$ enrichment in liver docosahexaenoate as in the controls.

In the liver of the control rats, about twice as much ${ }^{13} \mathrm{C}$ was recycled from ${ }^{13} \mathrm{C}$ - $\alpha$-linolenate into the sum of the principal saturated and monounsaturated fatty acids as was incorporated into docosahexaenoate. Almost half of the recycled ${ }^{13} \mathrm{C}$ in liver lipids of controls was found in palmitate. In the liver of the n-3 PUFA-deficient group, carbon recycling from ${ }^{13} \mathrm{C}-\alpha$ linolenate into other fatty acids was $45 \%$ higher (not significant), with the main increase occurring in palmitate $(p<0.05$; Table 2). In the liver, the ratio of ${ }^{13} \mathrm{C}$ incorporated into docosahexaenoate versus recycled into other fatty acids was not significantly different between the two groups.

Compared with controls, there was $82 \%$ less docosahexaenoate in the brain of the n-3 PUFA-deficient group (Table 3). $\alpha$-Linolenate and eicosapentaenoate were not reliably detected in the brain of either group so ${ }^{13} \mathrm{C}$ enrichment data were not available for these two n-3 PUFA. In the controls, four times more ${ }^{13} \mathrm{C}$ was present in brain docosahexaenoate as in brain $n-3$ docosapentaenoate. In the n-3 PUFA-deficient group,${ }^{13} \mathrm{C}$ enrichment was 3.5 -fold higher in brain n-3 docosapentaenoate but, for docosahexaenoate, did not change significantly from control values (Table 3 ).

Brain sterol content was the same (about $7.5 \mathrm{mg} / \mathrm{g}$ ) in both groups and was included in the calculation of the sum of carbon recycling for the brain. In the brain lipids of the controls, $31 \%$ of the ${ }^{13} \mathrm{C}$ recycled from $\alpha$-linolenate was in sterols, $55 \%$ was in saturates (myristate, palmitate, and stearate), and $14 \%$ was in oleate. There was $49 \%$ less ${ }^{13} \mathrm{C}$ recycling in the n-3 PUFA-deficient group than in the controls (Table 3 ), with a greater difference in ${ }^{13} \mathrm{C}$ labeling of sterols $(-71 \%)$ than fatty acids $(-43 \%)$. The lack of change in ${ }^{13} \mathrm{C}$ incorporation into brain docosahexaenoate and the lower recycling of ${ }^{13} \mathrm{C}$ from $\alpha$-linolenate into other brain lipids combined to reduce the excess of recycling versus docosahexaenoate synthesis from 7.5 -fold in the controls to 2.8 -fold in the $\mathrm{n}$-3 PUFA-deficient group $(-63 \% ; p<0.05)$.

\section{DISCUSSION}

The markedly reduced brain and liver content of n-3 PUFA in the n-3 PUFA-deficient rat pups was expected from our previous work with this model $(16,17)$ and demonstrated that severe deficiency of n-3 PUFA had been achieved. Our goal was to investigate whether carbon recycling of $\alpha$-linolenate was an apparent "overflow" pathway somehow linked to disposal of excess $\alpha$-linolenate when docosahexaenoate was 
Table 2. Fatty acid content and distribution of ${ }^{13} \mathrm{C}$ in the liver of the control and $n-3$ PUFA-deficient (Deficient) rats $24 \mathrm{~h}$ after dosing with $\left[U_{-}{ }^{13} C\right]-\alpha$-linolenate

\begin{tabular}{|c|c|c|c|c|}
\hline & \multicolumn{2}{|c|}{ Fatty acid content (mg/g) } & \multicolumn{2}{|c|}{${ }^{13} \mathrm{C}$ enrichment (ng ${ }^{13} \mathrm{C} /$ liver) } \\
\hline & Control & Deficient & Control & Deficient \\
\hline \multicolumn{5}{|l|}{ n-3 PUFA } \\
\hline$\alpha$-Linolenate & $0.2 \pm 0.1 *$ & $0.02 \pm 0.004 \dagger$ & $2318 \pm 465$ & $756 \pm 428 \dagger$ \\
\hline Eicosapentaenoate & $0.03 \pm 0.01$ & $<0.01$ & $12 \pm 13$ & ND \\
\hline Docosapentaenoate & $0.6 \pm 0.2$ & $0.02 \pm 0.01 \dagger$ & $124 \pm 92$ & $352 \pm 148 \dagger$ \\
\hline Docosahexaenoate & $2.9 \pm 1.3$ & $0.09 \pm 0.06 \dagger$ & $288 \pm 242$ & $673 \pm 642$ \\
\hline \multicolumn{5}{|l|}{ Other fatty acids $\ddagger$} \\
\hline Myristate & $2.5 \pm 0.6$ & $3.9 \pm 0.5 \dagger$ & $98 \pm 35$ & $180 \pm 89$ \\
\hline Palmitate & $9.9 \pm 1.3$ & $11.0 \pm 1.8$ & $263 \pm 115$ & $440 \pm 159 \dagger$ \\
\hline Palmitoleate & $0.6 \pm 0.1$ & $0.8 \pm 0.1 \dagger$ & $28 \pm 9$ & $22 \pm 12$ \\
\hline Stearate & $2.6 \pm 0.5$ & $2.1 \pm 0.8$ & $120 \pm 66$ & $80 \pm 78$ \\
\hline Oleate & $7.1 \pm 1.1$ & $8.2 \pm 1.5$ & $139 \pm 97$ & $222 \pm 149$ \\
\hline $\mathrm{Sum}^{2}$ & $22.7 \pm 3.1$ & $25.9 \pm 4.1$ & $649 \pm 151$ & $943 \pm 341$ \\
\hline Recycling§/docosahexaenoate & NA & NA & $2.4 \pm 1.9$ & $1.5 \pm 0.9$ \\
\hline
\end{tabular}

$* p<0.05$ versus controls.

$\dagger$ Mean \pm SEM of $n=10$ /group.

$\ddagger$ Excludes all n-3 and n-6 polyunsaturates.

$\S$ Recycling is the sum of ${ }^{13} \mathrm{C}$ in sterols and fatty acids excluding $\mathrm{n}-3$ and $\mathrm{n}-6$ polyunsaturates.

ND, not detectable; NA, not applicable.

Table 3. Lipid content and distribution of ${ }^{13} \mathrm{C}$ in the brain of the control and $n-3$ PUFA-deficient (Deficient) rats $24 \mathrm{~h}$ after dosing with $\left[U_{-}{ }^{13} C\right]-\alpha$-linolenate

\begin{tabular}{|c|c|c|c|c|}
\hline & \multicolumn{2}{|c|}{ Lipid content (mg/g) } & \multicolumn{2}{|c|}{${ }^{13} \mathrm{C}$ Enrichment (ng ${ }^{13} \mathrm{C} /$ brain) } \\
\hline & Control & Deficient & Control & Deficient \\
\hline \multicolumn{5}{|l|}{ n-3 PUFA } \\
\hline Docosapentaenoate & $0.1 \pm 0.04 *$ & $0.02 \pm 0.004 \dagger$ & $33 \pm 7$ & $115 \pm 41 \dagger$ \\
\hline Docosahexaenoate & $4.0 \pm 0.3$ & $0.7 \pm 0.3 \dagger$ & $129 \pm 44$ & $157 \pm 103$ \\
\hline Sterols & $7.4 \pm 0.2$ & $7.6 \pm 1.8$ & $276 \pm 196$ & $80 \pm 45 \dagger$ \\
\hline \multicolumn{5}{|l|}{ Other fatty acids $\dagger$} \\
\hline Myristate & $0.4 \pm 0.02$ & $0.5 \pm 0.1$ & $9 \pm 3$ & $4 \pm 3 \dagger$ \\
\hline Palmitate & $8.1 \pm 0.4$ & $7.1 \pm 0.9 \dagger$ & $388 \pm 94$ & $239 \pm 91 \dagger$ \\
\hline Stearate & $3.6 \pm 0.2$ & $3.1 \pm 0.7$ & $112 \pm 31$ & $49 \pm 39 \dagger$ \\
\hline Oleate & $4.0 \pm 0.3$ & $3.4 \pm 0.4 \dagger$ & $118 \pm 43$ & $66 \pm 36 \dagger$ \\
\hline Sum other fatty acids $\ddagger$ & $16.1 \pm 0.7$ & $14.1 \pm 1.8 \dagger$ & $627 \pm 167$ & $358 \pm 154 \dagger$ \\
\hline Recycling§/docosahexaenoate & NA & NA & $7.5 \pm 2.1$ & $2.8 \pm 2.0 \dagger$ \\
\hline
\end{tabular}

* Mean \pm SEM of $n=10$ /group.

$\dagger p<0.05$ versus controls.

+ Excludes all n-6 and n-3 polyunsaturates.

$\S$ Recycling is the sum of ${ }^{13} \mathrm{C}$ in sterols and other fatty acids excluding $\mathrm{n}-3$ and $\mathrm{n}-6$ polyunsaturates

NA, not applicable.

abundantly available during the suckling period or whether, as with n-6 PUFA deficiency, carbon recycling of $\alpha$-linolenate seems integral to its metabolism because it occurs even when tissue levels of longer chain PUFA are extremely depleted (11).

The ratio of ${ }^{13} \mathrm{C}$ recycling into other tissue lipids versus its incorporation into docosahexaenoate is a quantitative measure of carbon recycling from $\alpha$-linolenate. Among the various n-3 PUFA that could have been chosen, we focused this ratio on docosahexaenoate because of its central and irreplaceable role in the membrane phospholipids of many cell types, especially neurons. Accordingly, a high ratio of carbon recycling from $\alpha$-linolenate versus incorporation into docosahexaenoate implies that docosahexaenoate synthesis is a lower priority than overflow and vice versa. As in previous studies (3-7), the present results show that suckling rat pups receiving a normal supply of n-3 PUFA (the controls) recycle significantly more
${ }^{13} \mathrm{C}$ from $\alpha$-linolenate into newly synthesized lipids than they put into liver or brain docosahexaenoate. Under the conditions of this study, the recycling/docosahexaenoate ratio was 2.4 in the liver and 7.5 in the brain of the controls, but varies with the time point after dosing the tracer and with the organ or species in question $(7,10)$. In our model, severe n-3 PUFA deficiency curtailed carbon recycling from $\alpha$-linolenate, but, even in the deficient rat pups, this pathway was clearly still active and matched (liver) or exceeded (brain) ${ }^{13} \mathrm{C}$ incorporation from $\alpha$-linolenate into docosahexaenoate.

Under the present conditions, carbon recycling from $\alpha$-linolenate equals or exceeds conversion to docosahexaenoate even when 1) tissue docosahexaenoate is very low, 2) docosahexaenoate synthesis is typically stimulated (n-3 PUFA deficiency), and 3) the need for brain docosahexaenoate is probably higher than at any other time in the life cycle. Given analogous data from humans (10) and other models $(8,8 \mathrm{a}, 9)$, 
our present results add to the emerging body of evidence demonstrating that carbon recycling is an integral part of metabolism of $\alpha$-linolenate and, as with carbon recycling from linoleate (11), is not simply an overflow pathway arising from an abundance or excess of docosahexaenoate.

Comparing carbon recycling from $\alpha$-linolenate to synthesis of docosahexaenoate indicates little about the relative importance of either pathway. However, both pathways consume carbon from $\alpha$-linolenate so this comparison does provide a reference point from which the impact of dietary or metabolic manipulation on relative synthesis of docosahexaenoate can be evaluated. The brain has a high requirement for docosahexaenoate but not for other n-3 PUFA, so the fact that ${ }^{13} \mathrm{C}$ incorporation into lipid products of recycling from $\alpha$-linolenate normally exceeds by several fold $\alpha$-linolenate conversion to docosahexaenoate supports other studies showing that incorporation of preformed (consumed) rather than endogenously synthesized docosahexaenoate is likely to be an important way for the brain to obtain docosahexaenoate $(18,19)$. Why carbon recycling occurs so actively in the suckling period and in the face of high demand for docosahexaenoate is still unclear and will require further investigation.

Acknowledgments. This study was supported by the NIAAA Intramural Research Program (Y.H.L., S.Y.L., and NS) and by NSERC (S.C.C. and M.A.R.).

\section{REFERENCES}

1. Cunnane SC, Yang J 1995 Zinc deficiency impairs whole-body accumulation of polyunsaturates and increases the utilization of $\left[1-{ }^{14} \mathrm{C}\right]$ linoleate for de novo lipid synthesis in pregnant rats. Can J Physiol Pharmacol 73:1246-1252

2. Cunnane SC, Anderson MJ 1997 The majority of dietary linoleate in growing rats is $\beta$-oxidized or stored in visceral fat. J Nutr 127:146-152

3. Sinclair AJ 1975 Incorporation of radioactive polyunsaturated fatty acids into liver and brain of the developing rat. Lipids 10:175-184

4. Dhopeshwarkar GA, Subramanian C 1975 Metabolism of $\alpha$-linolenic acid in developing brain. I. Incorporation of radioactivity from $\left[1-{ }^{14} \mathrm{C}\right]-\alpha$-linolenic acid into brain fatty acids. Lipids 10:238-241
5. Dhopeshwarkar, Subramanian C 1975 Metabolism of $\alpha$-linolenic acid in developing brain. II. Incorporation of radioactivity from $\left[1-{ }^{14} \mathrm{C}\right]-\alpha$-linolenic acid into brain lipids. Lipids 10:242-247

6. Menard CR, Goodman KJ, Corso TN, Brenna JT, Cunnane SC 1998 Recycling of carbon into lipids synthesized de novo is a quantitatively important pathway of $\alpha$-[U- $\left.{ }^{13} \mathrm{C}\right]$-linolenate utilization in the developing rat brain. J Neurochem 71:21512158

7. Cunnane SC, Ryan MA, Nadeau CR, Bazinet RP, Musa-Veloso K, McCloy U 2003 Why is carbon from some polyunsaturates extensively recycled into lipid synthesis? Lipids 38:477-484

8. Williard DE, Harmon SD, Kaduce TL, Preuss M, Moore SA, Robbins ME, Spector AA 2001 Docosahexaenoic acid synthesis from n-3 polyunsaturated fatty acids in differentiated rat brain astrocytes. J Lipid Res 42:1368-1376

8a.Demar JC Jr, Ma C, Chang L, Rapoport SI 2005 alpha-Linolenic acid does not contribute appreciably to docosahexaenoic acid within brain phospholipids of adult rats fed a diet rich in docosahexaenoic acid. J Neurochem 94:1063-1076

9. Sheaff Greiner RC, Zhang Q, Goodman KJ, Guissani DA, Nathanielsz PW, Brenna JT 1996 Linoleate, $\alpha$-linolenate and docosahexaenoate recycling into saturated and monounsaturated fatty acids is a major pathway in pregnant or lactating adults and fetal or infant rhesus monkeys. J Lipid Res 37:2675-2686

10. Burdge GC, Wootton SA 2003 Conversion of $\alpha$-linolenic acid to palmitic, palmitoleic, stearic and oleic acids in men and women. Prostaglandins Leukot Essent Fatty Acids 69:283-290

11. Cunnane SC, Belza K, Anderson MJ, Ryan MA 1998 Substantial carbon recycling from linoleate into products of de novo lipogenesis occurs in rat liver even under conditions of extreme linoleate deficiency. J Lipid Res 39:2271-2276

12. Salem N Jr, Litman B, Kim HY, Gawrisch K 2001 Mechanisms of action of docosahexaenoic acid in the nervous system. Lipids 36:945-959

13. Salem N Jr. 1989 Omega-3 fatty acids: molecular and biochemical aspects. In: Spiller G, Scala J (eds) New Protective Roles of Selected Nutrients in Human Nutrition. Alan R. Liss, New York, pp 109-228

14. Lim SY, Doherty JD, McBride K, Miller-Ihli NJ, Carmona GN, Stark KD, Salem N Jr. 2005 Lead exposure and (n-3) deficiency during rat neonatal development affect subsequent spatial task performance and olfactory discrimination. J Nutr 135: 1019-1026.

15. McCloy U, Ryan MA, Pencharz PB, Ross RJ, Cunnane SC 2004 A comparison of the metabolism of eighteen-carbon ${ }^{13} \mathrm{C}$-unsaturated fatty acids in healthy women. J Lipid Res 45:474-485

16. Moriguchi T, Loewke T, Garrison M, Catalan JN, Salem N Jr 2001 Reversal of docosahexaenoic acid deficiency in the rat brain, retina, liver and serum. J Lipid Res 42: 419-427

17. Moriguchi T, Salem N Jr 2003 Recovery of brain docosahexaenoate leads to recovery of spatial task performance. J Neurochem 87: 297-309.

18. Su HM, Bernardo L, Mirmiran M, Ma XH, Corso TN, Nathanielsz PW, Brenna JT 1999 Bioequivalence of dietary $\alpha$-linolenic and docosahexaenoic acids as sources of docosahexaenoate accretion in brain and associated organs of neonatal baboons. Pediatr Res 45:87-93

19. Lefkowitz W, Lim SY, Lin Y, Salem N Jr. 2005 Where does the developing brain obtain its docosahexaenoic acid? Relative contributions of dietary alpha-linolenic acid, docosahexaenoic acid and body stores in the developing rat. Pediatr Res 57: $157-165$ 